\title{
ANALISIS KOMPENSASI DISPERSI MENGGUNAKAN PENGUAT RAMAN PADA JARINGAN WDM (WAVELENGTH DIVISION MULTIPLEXING) DALAM KOMUNIKASI SERAT OPTIK
}

\author{
Roby Ikhsan, Romi Fadli Syahputra, Saktioto* \\ Fakultas Matematika dan Ilmu Pengetahuan Alam, Universitas Riau \\ *E-mail korespondensi: saktioto@ieee.org
}

\begin{abstract}
The discovery of optical fiber cause widespread revolution of communication system. Optical fiber communication has excellency on data transmission speed, security, flexibility, and broadly bandwidth. The applying of WDM network can broaden the bandwidth so that the transmission performance becomes more splendid. Although some factors such as dispersion, attenuation, and scattering can hinder the performance of fiber optic on sending data. Moreover dispersion can wreck data and spread pulse as it travels alongs fiber so that causing interference. There is some methods of dispersion compensation. In this paper, Fiber Raman Amplifier is used on WDM network to strengthen signal which is sent to detector. This research utilize simulation approachment with various bandwidth and length fiber. The results show lowest BER value and highest $Q$-factor at bandwidth frequency of $30 \mathrm{GHz}$ and fiber length of $20 \mathrm{~km}$.
\end{abstract}

Keywords: WDM, Fiber Raman Amplifier, Dispersion Compensation, Optical Fiber Communication.

\begin{abstract}
ABSTRAK
Penemuan serat ispe menyebabkan terjadinya revolusi besar dalam isper komunikasi. Komunikasi serat ispe memiliki keunggulan dalam kecepatan transmisi data, keamanan, fleksibilitas, dan penyediaan bandwidth yang lebih lebar. Penggunaan jaringan WDM dapat memperbesar nilai bandwidth sehingga kinerja transmisi menjadi lebih baik. Namun, beberapa isper seperti isperse, atenuasi, dan hamburan dapat menghambat kinerja serat ispe dalam mengirimkan data. Terlebih lagi, isperse dapat merusak data dan menyebarkan pulsa saat melintasi serat sehingga terjadi interferensi. Telah banyak ditemukan metode sebagai kompensasi dispersi. Dalam makalah ini akan dibahas tentang jaringan WDM yang menerapkan Penguat Raman untuk memperkuat sinyal yang dikirim ke detektor. Penelitian ini menggunakan pendekatan simulasi dengan memvariasikan frekuensi bandwidth dan panjang serat optik. Hasil simulasi menunjukkan nilai BER terendah dan Q-factor tertinggi tercipta pada frekuensi bandwidth $30 \mathrm{GHz}$ dan panjang serat $20 \mathrm{~km}$.
\end{abstract}

Kata kunci: WDM, Penguat Raman, Kompensasi Dispersi, Komunikasi Serat Optik.

\section{PENDAHULUAN}

Komunikasi merupakan suatu proses penyampaian informasi dari satu pihak ke pihak lain melalui suatu media. Pemakaian kawat tembaga sebagai media tansmisi dalam sistem komunikasi tidak lagi memungkinkan untuk digunakan dalam transmisi data jarak jauh dengan kapasitas besar dan kecepatan yang tinggi. Dengan kendala inilah pemakaian kawat tembaga sebagai media transmisi digantikan oleh serat optik dengan kemampuan yang lebih tinggi [1].

Pada saat sekarang ini dibutuhkan pengembangan sistem komunikasi yang besar dengan laju perkembangan sistem telekomunikasi yang tinggi. Hal ini menyebabkan naiknya penggunaan Wavelength Division Multiplexing (WDM) dalam pengembangan jaringan optik. Sistem WDM mampu mentransmisikan data melalui suatu serat optik dan mengirim beberapa sinyal dengan panjang gelombang yang berbeda. Channel informasi yang berbeda dapat ditambahkan ke lokasi yang berbeda dengan menggunakan multiplexer. Penambahan ini dapat menambah fleksibilitas sistem WDM [2, 3 ,4]. Pengiriman sejumlah sinyal dibutuhkan bandwidth yang lebar dalam komunikasi optik. Hadirnya sistem WDM dapat memenuhi 
kebutuhan ini. Walaupun komunikasi ini tetap mengalami beberapa hambatan seperti dispersi. Dispersi merupakan suatu distorsi pada berkas cahaya yang melintas di dalam inti serat optik yang disebabkan oleh adanya mode (modus) dan panjang gelombang ataupun kecepatan yang berbeda. Dispersi menyebabkan terjadinya loss pada saat pengiriman data.

Terdapat beberapa teknik yang sudah dikembangkan sebagai kompensasi dispersi seperti penggunaan FBG [5, 6, 7, 8, 9]; Chirp Grating [10]; dan orthogonal frequency division multiplexing [11]. Teknik lain yang digunakan adalah penggunaan penguat optik. Penguat semikonduktor (SOA) dapat digunakan untuk memperkuat jaringan dengan lebar bandwidth di atas $20 \mathrm{GHz}$ [12]. Dalam makalah ini akan dilakukan kompensasi dispersi dengan menggunakan penguat Raman (FRA).

\section{METODE PENELITIAN}

Sistem dioperasikan secara komunikasi optik yang terdiri dari sebuah transmiter, medium transmisi, dan detektor. Sistem mentransmisikan informasi dari transmiter menuju detektor melalui serat optik. Simulasi ini menggunakan empat buah rangkaian transmiter yang memiliki spesifikasi spacing channel yang sama sebesar $50 \mathrm{GHz}$. Sinyal input berbentuk data elektrik dalam bentuk data bit 0 dan 1 yang dibangkitkan oleh nonreturn-to-zero (NRZ) pseudo random binary sequence. Sinyal input ini dimodulasi dengan laser Vertical Cavity Emitting Laser (VCEL) oleh Mach-Zehnder Modulator (MZM). Input sinyal VCEL memiliki frekuensi sebesar 193,1; 193,15; 193,2; dan 193,25 THz dan temperatur $20^{\circ} \mathrm{C}$. MZM memodulasi sinyal listrik dan sinyal cahaya, kemudian menghasilkan sinyal keluaran optik yang dikirimkan ke multiplexer 4x1.

Serat optik yang digunakan adalah Single Mode Fiber (SMF) karena dapat menghasilkan laju data lebih cepat, dispersi lebih sedikit, dan juga bisa beroperasi untuk jarak yang jauh sehingga cocok digunakan sebagai saluran transmisi. Dalam desain jaringan transmisi ini, SMF dioperasikan dengan dispersi 16,75 $\mathrm{ps} / \mathrm{nm} . \mathrm{km}$ dan atenuasi $0,3 \mathrm{~dB} / \mathrm{km}$. Dalam simulasi dengan variasi frekuensi bandwidth digunakan serat sepanjang $50 \mathrm{~km}$.

Simulasi menggunakan Fiber Bragg Grating (FBG) sebagai kompensasi dispersi dan penguat optik sebagai kompensasi rugi linier serat (atenuasi) yang dapat dilihat pada

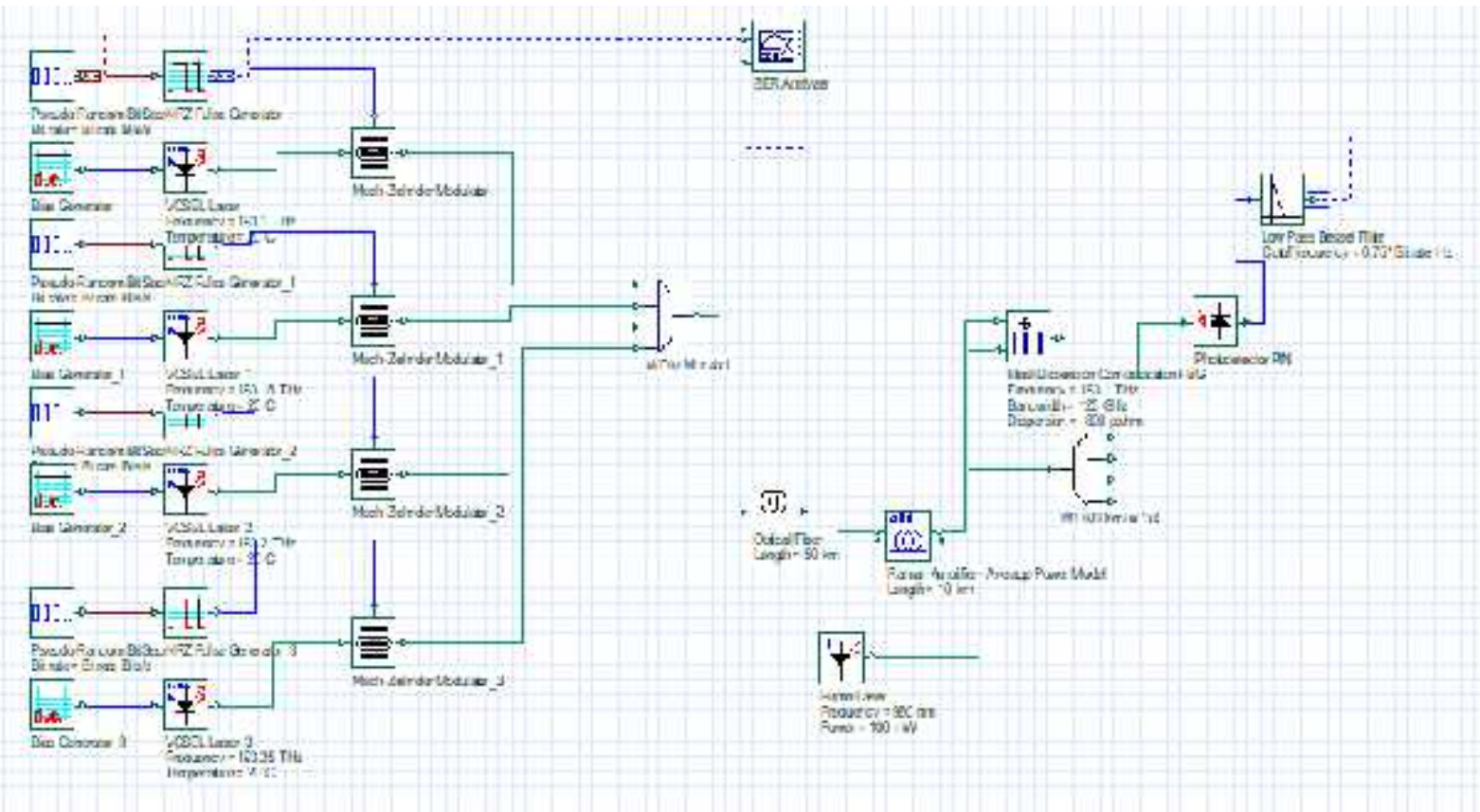

Gambar 1. Model simulasi sistem WDM dengan Penguat Raman 
Gambar 1. Rangkaian didesain untuk panjang serat $50 \mathrm{~km}$ dan digandengkan dengan Penguat Raman (frekuensi $980 \mathrm{~nm}$ dan daya $100 \mathrm{~mW}$ ), atenuasi serat $0,3 \mathrm{~dB} / \mathrm{km}$, dan frekuensi keempat channel yaitu $193.1 \mathrm{THz}, 193.15$ THz, 193.2 THz and $193.25 \mathrm{THz}$.

Pada bagian detektor, fotodetektor PIN dihubungkan ke keluaran untuk mendeteksi sinyal optik. Sinyal optik diubah kembali menjadi sinyal elektrik dan dikirimkan ke low pass Bessel filter yang hanya meloloskan sinyal berfrekuensi rendah dan menahan sinyal berfrekuensi tinggi. BER analyzer digunakan untuk mengukur laju bit yang error dan $Q$ factor dari desain sistem.

\section{HASIL DAN PEMBAHASAN}

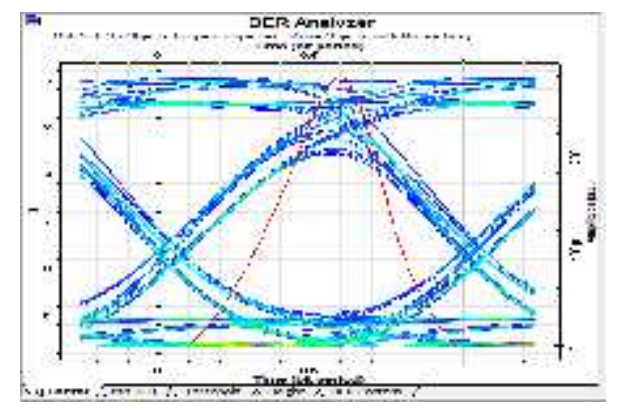

Gambar 2. Diagram mata pada bandwidth 10 GHz.

Simulasi pertama dilakukan dengan panjang serat optik dijaga konstan sepanjang $50 \mathrm{~km}$ dan bandwidth sebesar $10 \mathrm{GHz}$. Pada lebar bandwidth ini didapatkan nilai Q-factor sebesar 7,07. Nilai ini sudah memenuhi standar International [13] yaitu minimal bernilai 6 untuk sebagai acuan dapat tidaknya suatu rangkaian optik digunakan. Diagram mata (eye diagram) pada kondisi ini ditunjukkan pada Gambar 2. Hasil ini lebih baik jika dibandingkan dengan sistem WDM penguat SOA [12] dimana pada lebar bandwith yang sama Q-factor hanya bernilai 4,18. Diagram mata pada sistem Raman juga lebih halus dan tidak banyak terjadi pelebaran sinyal.

Jika bandwith dinaikkan hingga angka 20 $\mathrm{GHz}$, Q-factor mengalami peningkatan dan terjadi penurunan nilai BER. Pada lebar bandwidth ini didapatkan nilai Q-factor sebesar 10,65 dan nilai BER 8,60E-27. Diagram matanya (Gambar 3) lebih halus dan lebih sedikit sinyal yang melebar jika dibandingkan dengan bandwidth $10 \mathrm{GHz}$. Untuk lebar bandwidth di atas $20 \mathrm{GHz}$ hingga $50 \mathrm{GHz}$, nilai Q-factor mulai stabil.

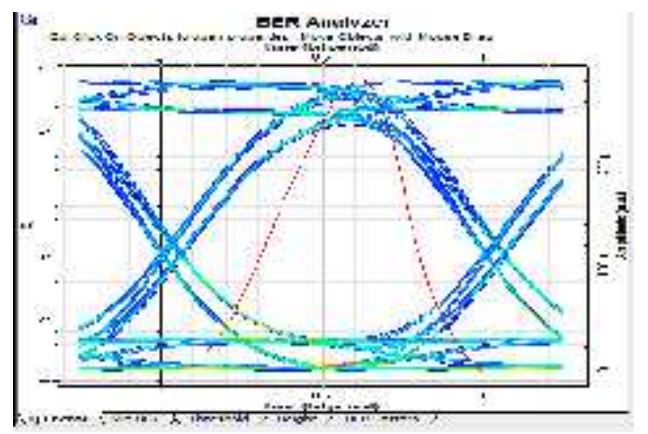

Gambar 3. Diagram mata pada Bandwidth 20 GHz.

Nilai Q-factor dan BER untuk variasi lebar bandwidth dapat dilihat pada Tabel 1 berikut ini:

Tabel 1. Nilai Q-factor dan BER terhadap variasi bandwidth.

\begin{tabular}{cccc}
\hline No & $\begin{array}{c}\text { Bandwidth } \\
(\mathrm{GHz})\end{array}$ & Q-factor & BER \\
\hline 1. & 10 & 7,07 & $7,26 \mathrm{E}-13$ \\
2. & 20 & 10,65 & $8,60 \mathrm{E}-27$ \\
3. & 30 & 11,16 & $3,16 \mathrm{E}-29$ \\
4. & 40 & 11,05 & $1,04 \mathrm{E}-28$ \\
5. & 50 & 10,81 & $1,54 \mathrm{E}-27$ \\
\hline
\end{tabular}

Gambar diagram mata untuk rangkaian tanpa penguat Raman dapat dilihat pada Gambar 4 berikut ini:

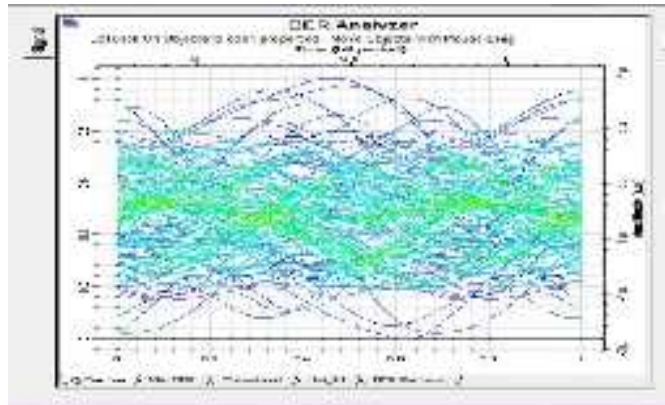

Gambar 4. Diagram mata untuk sistem WDM tanpa penguat Raman. 
Dari gambar di atas dapat dilihat bahwa diagram mata pada sistem tanpa penguat Raman berbentuk acak dan tidak teratur. Hal ini menandakan sinyal tidak dapat sampai ke detektor. Dengan adanya penguat Raman, bentuk diagram mata menjadi teratur dan menjadi lebih halus sehingga hal ini membuktikan bahwa penguat Raman dapat dijadikan sebagai kompensasi dispersi.

Simulasi kedua dilakukan dengan lebar bandwidth dijaga konstan sebesar $50 \mathrm{GHz}$ dan diawali dengan panjang serat optik $20 \mathrm{~km}$. Pada panjang serat ini didapatkan nilai Qfactor sebesar 9,29. Nilai Q-factor dan BER untuk setiap panjang serat optik dapat dilihat pada Gambar 5 berikut:

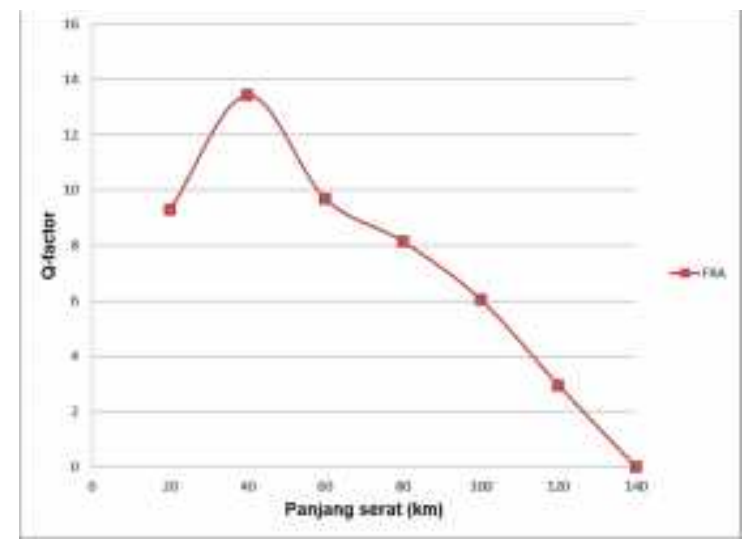

Gambar 5. Grafik Q-factor terhadap panjang serat optik.

Dari gambar tersebut dapat dilihat bahwa nilai Q-factor maksimum berada pada panjang serat $40 \mathrm{~km}$. Nilai Q-factor mengalami penurunan untuk panjang serat di atas $40 \mathrm{~km}$. Hal ini menunjukkan terjadinya dispersi pada sinyal yang merambat di dalam serat optik. Sistem masih dikatakan masih bagus untuk panjang serat di bawah $100 \mathrm{~km}$, sedangkan untuk panjang di atas itu tidak memenuhi aturan internasional mengenai komunikasi [13] dimana nilai Q-factor lebih kecil dari angka 6.

\section{KESIMPULAN}

Dalam makalah ini dibahas tentang jaringan WDM dengan menggunakan penguat Raman sebagai kompensasi dispersi. Sistem rangkaian didesain untuk panjang serat optik $50 \mathrm{~km}$ dimana frekuensi keempat channel yaitu 193,1; 193,15; 193,2; dan 193,25 THz dengan jarak channel yang sama sebesar 50 GHz. Simulasi pertama dijalankan dengan serat optik sepanjang $50 \mathrm{~km}$. Pada lebar bandwidth $20 \mathrm{GHz}$ didapatkan nilai BER terkecil dan $Q$-factor terbesar. Pada $10 \mathrm{GHz}$ pertama,Q-factor mengalami kenaikan hingga mulai stabil setelah mencapai $20 \mathrm{GHz}$. Simulasi kedua dijalankan dengan menjaga nilai bandwidth sebesar $50 \mathrm{GHz}$. Dengan menggunakan parameter yang diatur, sistem dapat mengirim sinyal hingga jarak $100 \mathrm{~km}$. Hal ini dibuktikan oleh nilai Q-factor yang bernilai di bawah angka 6 untuk jarak di atas $100 \mathrm{~km}$.

\section{REFERENSI}

1. Efriyanda, O., Faiza, D., \& Hadi, A. (2014). Analisis Kinerja Sistem Komunikasi Serat Optik dengan Menggunakan Metode Power Link Budget dan Rise Time Budget pada PT. Telkom (Studi Kasus Link Batusangkar-Lintau). Jurnal Vokasional Teknik Elektronika \& Informatika (VOTEKNIKA), 2(2): 80-86

2. Senior, J. M. \& Cusworth, S. D. (1989). Devices for Wavelength Multiplexing and Demultiplexing. Optoelectronics, IEEE Proceedings, 136(3) : 183-202.

3. Keiser, E. G. (1999). A Review of WDM Technology and Applications. Optical Fiber Technology, 5: 339.

4. Bujari, S. S. (2012). A survey on simulation of MEMS optical switch for WDM applications. World Journal of Science and Technology, 2(10): 39-43.

5. Othman, M. A., Ismail M. M., Sulaiman, H. A., Misran, M. H., Said, M. A. M., Rahim, Y. A., Che Pee, A. N., \& Motsidi, M. R. (2012). An Analysis of 10 Gbits/s Optical Transmission System using Fiber 
Bragg Grating (FBG). IOSR Journal of Engineering (IOSRJEN), 2(7): 55-61.

6. Prashad, B., Mallick, B., \& Parida, A. K. (2014). Fiber Bragg Grating as a Dispersion Compensator in an Optical Transmission System using Optisystem Software. International Research Journal of engineering and Technology (IRJET), 2(6): 9-14.

7. Kumar, K., Jaiswal, A. K., Kumar, M., \& Agrawal, N. (2014). Performance Analysis of dispersion compensation using Fiber Bragg Grating (FBG) in Optical Communication. International Journal of Current Engineering and Technology, 4(3): 1527-1531.

8. Singh, H., Sharma, N., \& Bharti, R. (2015). Analysis of Fiber Bragg Grating as Dispersion Compensator. International Journal of Engineering Research (IJOER), 1(3): 31-35.

9. Sharma, A., Singh, S., \& Sharma, B. (2013). Investigations on Dispersion
Compensation using Fiber Braggs Grating. International Journal of Computer Applications, 73(2): 34-43

10. Mohammadi, S. O., Mozzaffari, S., \& Shahidi, M. M. (2011). Simulation of a Transmission System to Compensate Dispersion in an Optical Fiber by Chirp Gratings. International Journal of the Physical Sciences, 6(32): $7354-7360$.

11. Lowery, A. J., Du, L., \& Armstrong, J. (2006). Orthogonal Frequency Division Multiplexing for Adaptive Dispersion Compensation in Long Haul WDM Systems. OFC OSA.

12. Hossain, M. S., Howlader, S., \& Basak, R. (2015). Investigating the Q-factor and BER of a WDM System in Optical Fiber Communication Network by using SOA. International Journal of Innovation and Scientific Research, 13(1): 315-322.

13. International Telecommunication Union TG. 691. 